\title{
Potencial e Disponibilidade de Biomassa de Cana-de-açúcar na Região Centro-Sul do Brasil: indicadores agroindustriais ${ }^{1}$
}

\author{
Natália de Campos Trombeta ${ }^{2}$ e José Vicente Caixeta Filho ${ }^{3}$
}

\begin{abstract}
Resumo: A energia termelétrica, em especial a produzida por meio de biomassa de canade-açúcar, é uma alternativa sustentável ao abastecimento e à segurança energética do País, uma vez que é complementar e substituta primária da energia hidrelétrica. Com isso, o estudo tem por objetivo identificar qualitativa e quantitativamente o potencial e a disponibilidade de biomassas de cana-de-açúcar para uso energético e como matéria-prima à futura tecnologia de produção de etanol celulósico na região Centro-Sul. Realizou-se um levantamento de dados para a safra 2013/14 com 77 usinas visando obter indicadores agronômicos (oferta de bagaço e palha de cana-de-açúcar), tecnológicos (potencial de cogeração do setor) e mercadológicos (preços de energia elétrica, participação nos ambientes de comercialização). De modo geral, os indicadores agronômicos para uma usina típica no Brasil apresentaram moagem média de 3 milhões de toneladas, $8,1 \%$ de impureza vegetal e $88 \%$ de colheita mecanizada. Os indicadores tecnológicos evidenciaram que mais de $60 \%$ das caldeiras amostradas apresentaram tecnologia de baixa pressão de vapor (até 48 bar) e $69 \%$ dos turbogeradores amostrados foram do tipo contrapressão simples. Já para os indicadores mercadológicos verificou-se, para as usinas que exportaram energia, que houve participação de 53\% no mercado regulado a preços médios de R\$ 191,49/MWh.
\end{abstract}

Palavras-chaves: Bagaço, palha, indicadores, cogeração, etanol celulósico.

Abstract: The thermoelectric power, in particular, produced by sugarcane biomass, shows up as a sustainable alternative to promote energy security. Thus, the study aims to identify qualitatively and quantitatively the potential and availability of biomass from sugarcane, bagasse and straw for energy use in cogeneration operation and as raw material for cellulosic ethanol production in South-Center region. In order to do this, a data collection was conducted for the 2013/14 season with 77 sugarcane mills to develop agronomic indicators (measurement of bagasse and straw sugarcane supply), technological indicators (industry cogeneration potential) and market indicators (electricity prices

1. Data de submissão: 11 de fevereiro de 2016. Data de aceite: 21 de maio de 2017.

2. Universidade de São Paulo, Escola Superior de Agricultura "Luiz de Queiroz", Departamento de Economia, Administração e Sociologia, Piracicaba, São Paulo, Brasil. E-mail: natalia.ctrombeta@gmail.com

3. Universidade de São Paulo, Escola Superior de Agricultura “Luiz de Queiroz”, Departamento de Economia, Administração e Sociologia, Piracicaba, São Paulo, Brasil. E-mail: jose.caixeta@usp.br 
and participation in different marketing environments). In general, agronomic indicators for a typical sugarcane mill in Brazil have medium crush of 3 million tons of sugarcane, $8.1 \%$ of plant impurity and $88 \%$ of mechanized harvesting. Technological indicators in Brazil showed that almost $60 \%$ of sampled boiler had a low vapor pressure technology (until 48 bar) and $69 \%$ of sampled turbogenerator were simple counter type. As for the market indicators, for energy exported mills, the share was $53 \%$ in the regulated market at an average price of $191.49 \mathrm{BRL} / \mathrm{MWh}$.

Key-words: Bagasse, sugarcane straw, indicators, cogeneration, cellulosic ethanol.

Classificação JEL: C43, L1, Q4.

DOI: http://dx.doi.org/10.1590/1234-56781806-94790550304

\section{Introdução}

Em um cenário formado pelo crescimento populacional e enriquecimento de países em desenvolvimento, a demanda por alimentos e energia tem se tornado um desafio aos grandes centros de produção e consumo. Além disso, os novos paradigmas relacionados à mitigação de impactos ambientais, dentre eles a minimização das emissões de gases do efeito estufa, reforça a necessidade de obtenção de fontes alternativas, limpas e renováveis de energia.

Nesse sentido, a busca por outras fontes e formas de geração de energia e a diversificação da matriz energética do Brasil são crescentes e providenciais, com destaque à energia termelétrica como a substituta primária à fonte hidrelétrica no País. Corroborando essa tendência e com base nas informações disponibilizadas pelo Operador Nacional do Sistema Elétrico (ONS), verificou-se, nos últimos dez anos (2005 a 2014), uma evolução anual média na oferta de energia térmica de aproximadamente $20 \%$ a.a. Em contrapartida, as demais fontes somadas, para o mesmo período, indicaram taxa anual média de crescimento de cerca de $3 \%$ a.a. Tais indicadores reforçam a estratégia de manutenção da segurança energética, tendo a fonte térmica um importante papel no suprimento de energia elétrica no País.

Dentre as matérias-primas utilizadas nas usinas termelétricas, a biomassa tem se destacado como um produto renovável e com elevado potencial de uso na geração de energia elétrica.
Enfatizando as biomassas oriundas da indústria da cana-de-açúcar, deve-se reconhecer inicialmente a histórica importância do setor canavieiro nas economias paulista e brasileira. Responsável, respectivamente, pelas primeiras e segundas colocações na produção de açúcar (USDA, 2015) e etanol (RFA, 2015) no mundo, este setor vem protagonizando um novo segmento em crescente ascensão: o energético.

Nesse contexto, o recentemente denominado setor sucroenergético vem se destacando não somente como o fornecedor da matéria-prima com maior balanço energético para produção de etanol, mas também pelos produtos secundários gerados no processamento da cana-de-açúcar. Tais subprodutos, até poucas décadas majoritariamente descartados, têm se tornado potenciais matérias-primas à cogeração de energia elétrica e à produção de etanol de segunda geração, por meio da hidrólise da celulose e hemicelulose da palha (restos vegetais deixados no campo após a colheita mecanizada) e bagaço (produto originado após a moagem da cana-de-açúcar).

Relativamente ao bagaço, o setor sucroenergético tem apresentado um nível técnico de utilização bastante maduro na curva de aprendizado dessa biomassa no que se diz respeito à cogeração e ao autoabastecimento das usinas com energia elétrica. Apesar disso, são notórias as diferenças tecnológicas entres as unidades produtivas, evidenciando grande variação de eficiência e capacidade. Em relação ao uso da palha, verifica-se reversão da tendência de ínfima exploração pelas usinas, reflexo da gradativa adequa- 
ção do setor a Lei Estadual n. 11.241 de eliminação da prática de queima de cana-de-açúcar até 2017, reforçada, em algumas regiões, pela assinatura do Protocolo Agroambiental, que acelerou o prazo do fim da queima para 2014. Nesse sentido, a palha vem sendo alvo de estudos econômicos, agronômicos e ambientais a fim de identificar sua real disponibilidade nos ambientes de produção e potencial uso como biomassa carburante ou matéria-prima para obtenção de etanol de segunda geração.

Englobando as expectativas supracitadas situam-se dois mercados estratégicos principais e passíveis à entrada da biomassa de cana-de-açúcar: 1. Mercado de Energia Elétrica e 2. Mercado de Biocombustíveis - Etanol. A compreensão das principais variáveis de impacto nesses mercados e a prospecção de suas tendências futuras são fundamentais à análise do potencial da biomassa como recurso produtivo e oportunidades de negócios no setor.

Nesse contexto, este estudo tem por objetivo identificar qualitativa e quantitativamente o potencial e disponibilidade de biomassas de cana-de-açúcar, bagaço e palha, para uso energético na operação de cogeração e como matéria-prima à futura tecnologia de produção de etanol de segunda geração no setor sucroenergético da região Centro-Sul. Especificamente, a pesquisa visa a geração de indicadores quantitativos e qualitativos de ordem agronômica, de tecnologia industrial e mercadológica para subsidiar de forma abrangente e transparente o objetivo geral anteriormente citado.

\section{Fundamentação teórica}

A participação da biomassa de cana-de-açúcar na produção e comercialização de energia elétrica vem aumentando nos últimos anos (Figura 1). É importante pontuar que a matriz energética brasileira, embasada na oferta hídrica, cujos preços são modelados considerando tal característica (nota-se pela Figura 1 que em períodos de estiagem nos grandes centros de consumo os preços de energia tendem a se elevar), a energia de biomassa mostra-se estratégica à segurança energética do País pela sua complementariedade a essa fonte, uma vez que os períodos tipicamente mais secos são, também, os de maior produção canavieira (abril a novembro). Do ponto de vista setorial e econômico, além de garantir a autonomia energética, parte das unidades

Figura 1. Geração térmica a biomassa (MWmédio) e PLD (R\$/MWh), 2010 a 2016 (out)

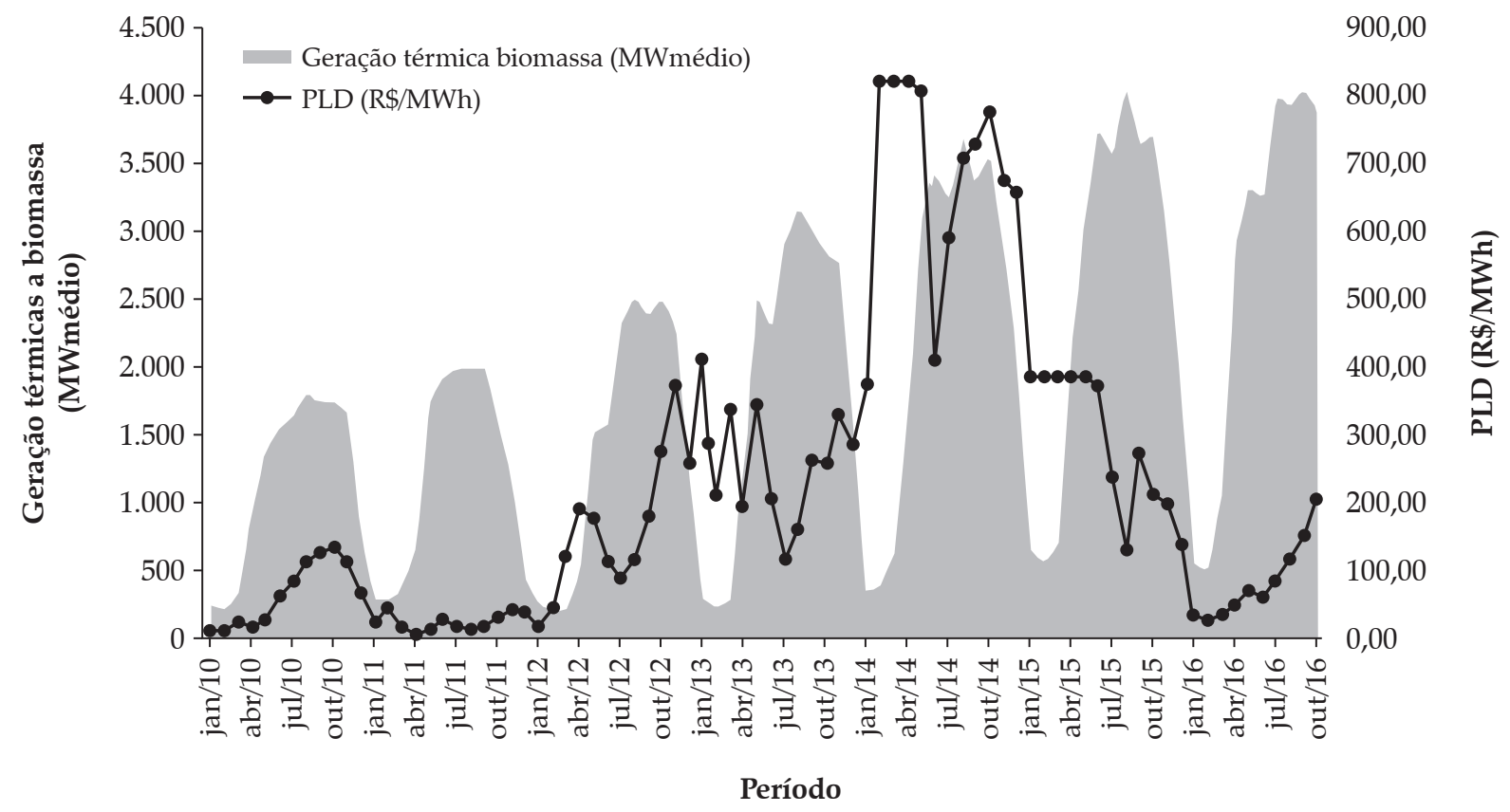

Fonte: CCEE (2016), PLD: Preço de Liquidação das Diferenças. 
sucroalcooleiras do País tem aumentado suas receitas com a comercialização da energia elétrica excedente gerada pela queima de biomassa.

Nesse contexto, as expectativas para o uso da energia de biomassa são positivas. A partir dos estudos desenvolvidos pelo Plano Nacional de Energia 2030 (EPE, 2006), ainda se verifica potencial de aumento da capacidade tecnológica industrial, a qual deve ampliar o processamento de biomassa de cana-de açúcar e produção de energia elétrica excedente. De acordo com o estudo desenvolvido pelo Ministério de Minas e Energia junto à Empresa de Pesquisa Energética (EPE), entre 2005 e 2030 a capacidade de geração deve aumentar 19 vezes, motivada também pelas expectativas de aumento do Produto Interno Bruto (PIB) e da demanda por energia elétrica no Brasil.

Tecnicamente, o termo cogeração no setor canavieiro vincula-se à produção de energia térmica transformada pelo vapor oriundo da queima de biomassas (bagaço e palha) nas caldeiras (UNICA, 2010). Essa energia térmica transforma-se em energia mecânica que promove o funcionamento das moendas, extratores e turbogeradores em que, nesses últimos, tem-se a geração de energia elétrica (UNICA, 2010). A energia mecânica destina-se ao funcionamento de moendas enquanto que a elétrica pode ter várias aplicações, em especial às atividades internas da usina (produção de açúcar e etanol) e exportação para o sistema interligado nacional (SOUZA, 2003). Em anos recentes a introdução de motores elétricos para o acionamento dos equipamentos de preparo e moagem da cana tem promovido a substituição das turbinas a vapor das moendas, proporcionando maior eletrificação ao sistema e aumento de exportação de energia à rede (tecnologia de maior eficiência).

Souza (2003) identificou que a baixa eficiência na geração e/ou aproveitamento de energia se deve ao fato de a maior parte das usinas apresentar caldeiras de baixa pressão de vapor (aproximadamente 22 bar), implantadas principalmente na década de 1970, com o Programa Nacional do Álcool (Proálcool). Nesse período, o ciclo de baixo rendimento energético foi predominante, uma vez que o produto energia não era priorizado (DANTAS FILHO, 2009).

Ainda nesse sentido, estudo realizado por CTC (2010 apud LOPES, 2013) mostrou que, em 2010, para uma amostra de 285 caldeiras do setor sucroenergético brasileiro, apenas $19 \%$ da tecnologia apresentava menos de 10 anos, 39\%, acima de 30 anos e 70\%, mais de 20 anos de implantação, corroborando o cenário de baixa eficiência geradora supracitada.

Nesse contexto, de acordo com Perdoná (2014), as tecnologias de caldeiras evoluíram ao longo dos anos, apresentando, em períodos recentes, caldeiras com até 100 bar de pressão, capazes de gerar excedentes de energia de até 110 KWh por tonelada de cana moída. Essa evolução na capacidade de geração de vapor das caldeiras foi acompanhada pelo desenvolvimento de novos tipos de caldeiras, como as de grelha rotativa, leito fluidizado, maior porte de equipamentos, novas tecnologias de turbogeração à condensação (que reduziu em quase pela metade o consumo específico do equipamento).

De acordo com Lopes (2013), as principais tecnologias comerciais disponíveis referem-se a: 1 . Ciclo de Vapor Tradicional de Contrapressão com reforma ou retrofit para aumento de eficiência de geração e 2 . Ciclo de Condensação e Extração. Em escala laboratorial, a gaseificação da biomassa mostra-se como uma tecnologia futura e promissora. No que se diz respeito ao retrofit das unidades produtivas com ciclos tradicionais, tem-se a substituição das turbinas a vapor de simples estágio para múltiplos estágios e caldeiras de baixa para elevada pressão. Já a alternativa vinculada ao ciclo de condensação e extração, além de promover maior rendimento produtivo ao longo do ano (a presença de condensadores permite a geração de energia na entressafra em virtude de a mesma não estar vinculada ao consumo de vapor no processo), aumenta a eficiência na geração de energia (LOPES, 2013).

No que diz respeito a projeções da participação das biomassas de cana-de-açúcar na matriz energética nacional, estudo decenal da Empresa de Pesquisa Energética - EPE (2015) indicou que o potencial técnico de geração de energia para 2023, tendo como matérias-primas o bagaço e a palha de cana-de-açúcar, é de 19,5 GW médios, o que equivale a aproximadamente $14 \%$ da matriz energética atual. As projeções da União da Indústria de Cana-de-Açúcar - Unica (2010) indicam um potencial de exportação de energia elétrica a partir de bagaço de aproximadamente 13 GW médios para a safra 2020/21 ou 9,5\% da matriz energética atual. Atualmente, segundo informações da Aneel (2014), a cogeração de energia elétrica excedente a partir da biomassa de cana-de-açúcar representa, em potência instalada, 9,73 GW ou 7\% da matriz energética nacional. 
Mercadologicamente, a energia elétrica gerada e exportada pelas usinas de cana-de-açúcar pode ser comercializada em dois ambientes de comercialização: 1. Ambiente de Comercialização Regulado (ACR) e 2. Ambiente de Comercialização Livre (ACL). Para o ACR, a comercialização de energia elétrica se dá por meio dos leilões de energia. O setor sucroenergético iniciou sua participação nessa modalidade em 2005, promovendo a negociação, até o último leilão de 2014, de aproximadamente 212 mil GWh, a serem gerados em períodos médios de 20 anos (CCEE, 2014). Nos dez anos de participações nos leilões de energia, foram formalizados 2197 contratos com aproximadamente 70 usinas de cana-de-açúcar, a um preço médio de R\$180,00/MWh (CCEE, 2014). Os preços tetos dos leilões de energia podem oscilar dependendo do tipo de leilão e competição entre diferentes fontes de geração como hidrelétrica e eólica. Nos últimos leilões tem havido a divisão dos contratos por fonte de fornecimento, viabilizando e diversificando a matriz energética contratada.

Sobre os tipos de leilóes, predomina a modalidade denominada como "Leilões de Energia Nova", cuja contratação visa ampliar a capacidade de geração de carga das unidades vencedoras do leilão. Nesse caso, o fornecimento de energia inicia-se de três a cinco anos após o ano-base do leilão, com contratos de fornecimento de 20 e 25 anos respectivamente (CCEE, 2014).

Para o ambiente de comercialização livre, a participação do setor canavieiro é desconhecida, uma vez que os dados não são públicos. Verifica-se considerável pulverização de empresas comercializadoras e distribuidoras de energia. Para esse ambiente de comercialização é utilizado o preço de liquidação das diferenças (PLD), o qual tem grande correlação negativa com o nível dos reservatórios, fazendo com o que a rentabilidade da comercialização da bioeletricidade canavieira seja mais competitiva em períodos de estiagem (UNICA 2010). Em 2014 o PLD apresentou comportamento atípico, reflexo da estiagem generalizada que atingiu os principais centros de consumo do País, o que reduziu a oferta de eletricidade. Os elevados valores, que ultrapassaram os R\$ 800,00/MWh em determinados meses do ano-safra 2014/15 (CCEE, 2014), fizeram com que a comercialização de energia, em algumas usinas, fosse a principal responsável por resultados positivos, uma vez que a safra referenciada apresentou uma série de problemas climáticos (redução na produção) e econômicos (preços poucos competitivos do etanol).
Em concordância ao potencial energético das biomassas de cana, outro mercado que terá grande influência dessa matéria-prima é o de combustíveis de segunda geração, como o etanol. De modo simplificado a tecnologia produtora do etanol de segunda geração, o E2G, como é denominado no setor, refere-se à produção do biocombustível a partir da hidrólise da celulose e hemicelulose (hexoses e pentoses) de biomassas como bagaço e palha de cana-de-açúcar, gerando moléculas simples como glicoses e xiloses passíveis à fermentação e à produção de etanol (MILANEZ et al., 2015). Comercialmente, a tecnologia supracitada apresenta poucos representantes no setor e ainda apresenta-se em fase de desenvolvimento; porém, deve ser efetivamente adotada no médio prazo em virtude, principalmente, do aumento da demanda nacional por etanol e compromissos ambientas de redução de emissões de gases do efeito estufa (MILANEZ et al., 2015).

Relativamente às biomassas de cana-de-açúcar, dentre os produtos residuais do setor sucroalcooleiro, o bagaço é a matéria-prima de maior abundância no complexo industrial brasileiro (SOUZA, 2003). Analisando-se o histórico de uso do bagaço de cana-de-açúcar, inicialmente tal produto mostrava-se como substituto à lenha, sendo incinerado nas caldeiras das unidades produtivas em quantidades superestimadas, fato que justifica, em parte, a existência de tecnologias industriais de baixa eficiência energética. Além disso, os excedentes de bagaço promoveram o surgimento de um mercado irregular, específico a cada região e com preços sazonalmente voláteis (DANELON et al., 2015).

Danelon et al., (2015) levantaram informações sobre o mercado de biomassa nas regiões de Goiás e Minas Gerais para a safra 2012/13, verificando que a venda do excedente de bagaço se vincula a quatro fatores principais: 1 . Custo de oportunidade de geração e comercialização de energia elétrica (dependente do preço da elétrica, custo de geração e existência de contratos de fornecimento pela unidade produtiva); 2. À distância entre as regiões ofertantes e demandantes; 3. À existência de substitutos diretos (cavaco de madeira) e 4. À influência de outras indústrias na região. Para o estudo em específico, as indústrias de tomate e de soja apresentaram grande impacto na dinâmica de comercialização de bagaço, especialmente para usinas com baixo nível tecnológico de cogeração.

Relativamente à viabilidade econômica do uso de biomassa, o estudo de caso em quatro usinas de 
cana-de-açúcar desenvolvido por Dantas Filho (2009) objetivou analisar os custos relativos ao processo de cogeração de energia elétrica por meio do bagaço, bem como as tendências de investimento em tais tecnologias. Os resultados médios de VPL (valor presente líquido) foram todos positivos com TIR (taxa interna de retorno) superiores à taxa de oportunidade considerada (em média 33\%) e payback de aproximadamente seis anos, evidenciando viabilidade econômica no investimento para ampliação do parque gerador das usinas avaliadas. Além da venda de energia excedente, o estudo avaliou a possibilidade de venda de emissões certificadas limpas e a economia de custos em energia de processo.

Oliveira et al. (2006) realizaram uma análise de viabilidade técnico-econômica no uso de biomassas substitutas ao coque de petróleo como matérias-primas para geração de energia em uma empresa situada na região de Ribeirão Preto (SP). Como resultados, as melhores classificações foram verificadas para as biomassas bagaço de cana-de-açúcar e resíduos de madeira. Esses produtos foram introduzidos em um modelo matemático visando a otimização na utilização de biomassa a partir, principalmente, dos custos de aquisição. A análise econômica dos resultados identificou a variável distância de captação como a principal restrição e impacto no custo e escolha da biomassa a ser adotada na empresa. Desse modo, apesar do impacto do transporte no custo médio, o bagaço de cana-de açúcar apresentou grande potencial como matéria-prima para indústrias cogeradoras, influenciando, sobretudo, a criação mais formalizada de um mercado para tal biomassa (OLIVEIRA et al., 2006).

Seabra (2008) analisou a viabilidade técnica e econômica da cogeração em uma usina média com moagem de 2 milhões de toneladas de cana sob sete diferentes cenários tecnológicos. De modo geral, os resultados indicaram que a substituição das caldeiras para modelos com maior pressão de vapor (de 22 bar para 65 ou 90 bar), bem como a adoção da nova tecnologia de turbogeradores (de contrapressão para extração - mais econômicos no uso de vapor pelos processos), aumentaram consideravelmente a quantidade de energia excedente gerada no sistema.

Defilippi Filho (2013) analisou a viabilidade no uso de palha de cana-de-açúcar a fim de estender o período de cogeração de energia elétrica em uma usina localizada no estado de São Paulo, com moagem aproximada de 2,5 milhões de toneladas de cana. Os resultados indicaram que para o cenário A (operação em 30 dias na entressafra), o projeto de aproveitamento de palha mostrou-se viável quando o custo da palha ficou abaixo dos $R \$ 49,00 / t$ ou preços de energia acima de R\$ 193,00/MWh. Para o cenário B (operação em 60 dias de cogeração na entressafra), o VPL encontrado foi positivo, com TIR superior à taxa de oportunidade adotada $(13,02 \%)$. Por fim, para o cenário C (operação em 90 dias na entressafra), a taxa de retorno superou os $25 \%$, com VPL sustentável à incorporação e/ou investimento no projeto.

Ainda sobre o uso de palha de cana-de-açúcar para geração de energia elétrica no setor, Leal et al. (2013) evidenciaram a importância e o impacto da palha remanescente no campo (após a colheita) sob os aspectos agronômicos, econômicos e energéticos. De modo geral, a disponibilidade de palha é variável de acordo com a produtividade, o número de cortes e a variedade de cana-de-açúcar cultivada, obtendo-se, em média, 15 t de palha em base seca por hectare de cana-de-açúcar. Seu uso, a princípio, pode se destinar à cogeração de energia elétrica ou para a segunda geração de biocombustível.

Comparativamente ao bagaço, a qualidade e a composição química da palha - dividida em folhas secas $(62 \%)$, folhas verdes $(31 \%)$ e ponteiros $(7 \%)$ mostrou parâmetros de carbono, poder calorífico, cinzas e carbono fixado semelhantes. No entanto, as quantidades de cloro e de potássio (especialmente nos ponteiros) mostraram-se consideravelmente superiores ao bagaço, implicando tendência de corrosão da superfície das caldeiras (LEAL et al., 2013).

Dentre as rotas utilizadas para recolhimento de palha, Hassuani et al. (2005) avaliaram cinco formatos distintos, sendo dois deles relativos à colheita integral de cana-de-açúcar, os quais foram descartados pela ausência de tecnologia viável a esse processo. Outras três rotas avaliadas foram: 1. Enfardamento de palha - Colheita de cana com retirada total da palha dos colmos; 2. Colheita de cana sem a limpeza de palha desligamento dos ventiladores de limpeza de palha carregando-a junto ao transporte para a recepção da usina, na qual deve haver estrutura específica denominada de sistema de limpeza a seco e 3. Colheita de cana com limpeza parcial de palha - com alteração das velocidades de trabalho dos ventiladores do extrator primário e desligamento do extrator secundário - deixando 
parte da palha no campo e carregando o restante junto ao transporte para a recepção da usina, na qual deve haver, também, um sistema de limpeza a seco.

Nos três processos avaliados, os custos e as eficiências de coleta e separação de palha foram bastante distintos. Para as rotas 1, 2 e 3 conseguiu-se recolher $88 \%, 95 \%$ e $71 \%$ de toda a palha disponível no campo, respectivamente. Já a eficiência de separação das impurezas minerais e vegetais dos colmos na usina foi sensivelmente baixa, com $64 \%$, $66 \%$ e $50 \%$ nos três casos, respectivamente. Quanto aos custos da palha em base seca, a alternativa 1 foi de US\$ 18.50/t, alternativa 2 , de US\$31.12/t e alternativa 3, de US\$13.70/t (HASSUANI et al., 2005).

A escolha da rota de recolhimento de palha deve considerar uma série de fatores agroindustriais inerentes a cada usina. Além disso, a quantidade de palha recolhida pode não ser homogênea, dependendo da produtividade do talhão, da rota de recolhimento, da temperatura de colheita etc. Nesse sentido, a adaptação da unidade a mais de uma rota de recolhimento de palha pode ser estratégica (LEAL et al., 2013).

Em suma, dada as expectativas positivas no uso das biomassas de cana-de-açúcar, bem como a viabilidade econômica de sua utilização no setor, faz-se fundamental e foco desse trabalho o conhecimento de indicadores agroindustriais e mercadológicos para identificação e quantificação do potencial dessa matéria-prima para o suprimento energético regional e nacional.

\section{Metodologia}

A fim de quantificar o potencial e disponibilidade de bagaço e palha de cana-de-açúcar para uso energético como matéria-prima à cogeração de energia elétrica e à produção de etanol de segunda geração, realizou-se um levantamento de dados primários junto às unidades produtivas da região Centro-Sul do Brasil e de dados secundários nos principais órgãos estatísticos do setor canavieiro e energético.

Sobre o levantamento de dados primários, este foi realizado por meio de vias eletrônica e telefônica, entre maio e novembro de 2014, visando obter informações para geração de três indicadores principais, referenciados na Figura 2: A. Agronômico; B. Tecnológico e C. Mercado. O questionário foi criado por meio da ferramenta Google Docs solicitando dados da safra 2013/14, cujo conteúdo pode ser acessado por meio do link https://docs.google.com/forms/d/e/1FAIpQLSfG8P5fB y272OIGfXwCFOQoH2AyftkI9qrZ0Mfh7x83AEP5vg/ viewform.

Em relação ao conteúdo do levantamento (Figura 2), as perguntas vinculadas ao bloco A (Agronômico) tiveram por objetivo: 1 . Dimensionar a capacidade produtiva de cada usina, incluindo moagem, área colhida e quantidade de dias em moagem (dias de safra) e 2. Estimar a disponibilidade de palha e bagaço de cana-de-açúcar em cada unidade. Por meio dos indicadores médios relativos à impureza vegetal, infere-se a

Figura 2. Fluxograma esquemático da oferta de energia elétrica no Brasil, sob a ótica do setor sucroenergético

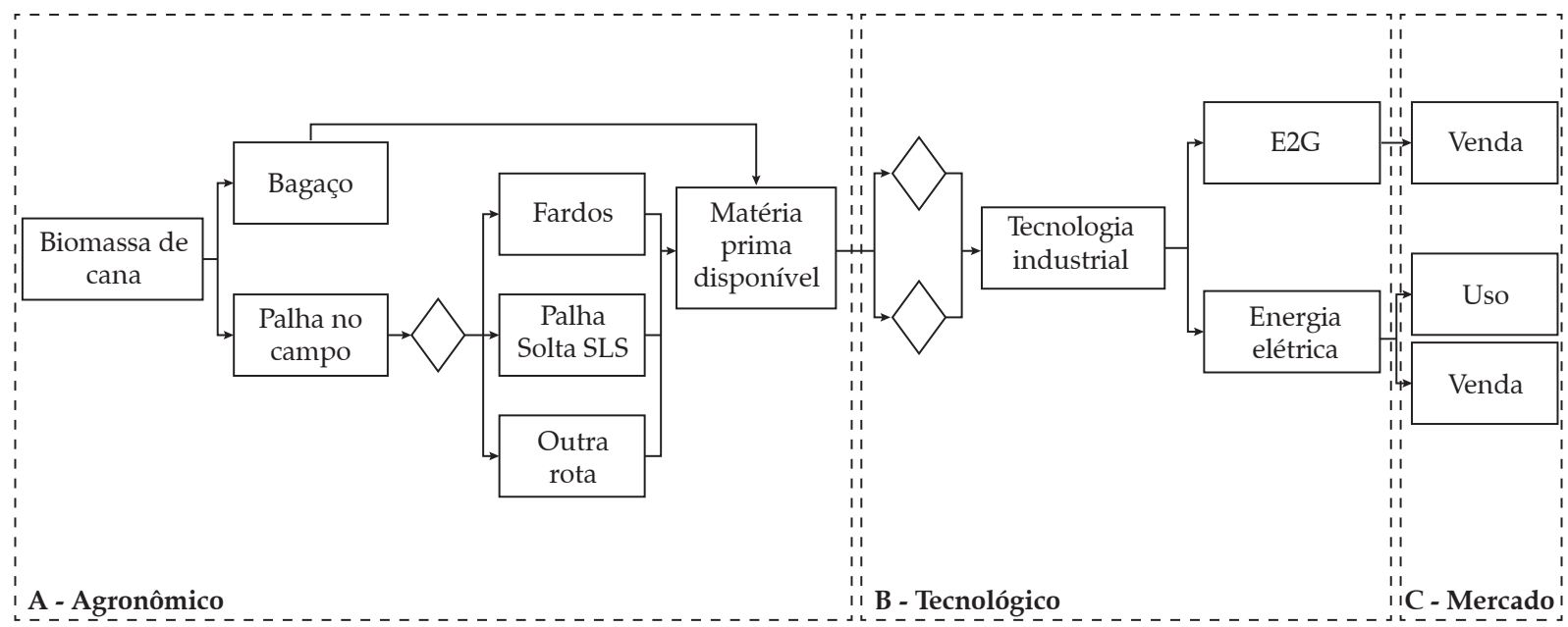

Fonte: Trombeta (2015). 
Tabela 1. Representatividade da amostra para a safra 2013/14

\begin{tabular}{lccc}
\hline \multicolumn{1}{c}{ Variáveis } & Amostra & Centro-Sul & Representatividade (\%) \\
\hline Número de Usinas & 77 & 295 & $26 \%$ \\
Moagem Total (t) & 225.618 .663 & 597.061 .000 & $38 \%$ \\
Área Colhida Total (t) & 2.750 .013 & 6.764 .991 & $41 \%$ \\
Quantidade de Caldeiras & 222 & - & - \\
Quantidade de Turbogeradores & 223 & - & - \\
Capacidade Instalada (MW) & 4.435 & 8416 & $53 \%$ \\
Exportação de Energia (MWh/safra) & 8.311 .845 & - & - \\
\hline
\end{tabular}

Fonte: Trombeta (2015), Unica (2014 - moagem), Conab (2014 - área, excluídos 12\% referentes à taxa de renovação de canavial) e Aneel (2014 - capacidade instalada).

quantidade média de palha (componente majoritário) incorporada à massa de cana-de-açúcar obtida no processo de colheita, devendo esse percentual ser contabilizado na quantidade de biomassa disponível na usina e posteriormente no sistema.

Além disso, a identificação de estruturas específicas para recepção de palha tais como Sistemas de Limpeza a Seco e Enfardamento, evidencia maior capacidade específica de recolhimento de palha no campo, diferente da situação de moagem da cana junto à palhada colhida.

Quanto ao bloco B, as variáveis industriais questionadas buscaram atualizar a condição tecnológica das unidades participantes no que se diz respeito ao número, idade, capacidade e tipo de caldeiras e de turbogeradores. Ainda nesse sentido, foram levantadas informações quanto ao consumo específico, quantidade de energia exportada à rede elétrica e posicionamento da unidade quanto à limitação de $30 \mathrm{MW}^{4}$ de exportação de energia para obtenção de desconto na TUSD (tarifa de uso dos sistemas elétricos de distribuição) e TUST (tarifa de uso dos sistemas elétricos de transmissão).

Por fim, o bloco $\mathrm{C}$, relativo ao mercado, teve por objetivo identificar quais são as unidades produtivas que participaram ou participam de leilões de energia, proporção de venda no mercado livre, bem como os preços médios recebidos em cada uma das duas condições anteriormente citadas. Buscou-se também compreender o comportamento regional do mercado de biomassas (bagaço, palha e outras biomassas), tais como preços praticados e quantidade comercializada.

4. Lei no 9.427 de 1996 estabeleceu que empreendimentos com base em fonte biomassa seriam beneficiados por desconto não inferior a 50\% aplicado à TUST e à TUSD para potência injetada igual ou inferior a $30 \mathrm{MW}$.
De posse dessas informações, agrupou-se os dados secundários obtidos junto à Unica, à Aneel e ao CTC - Benchmarking ${ }^{5}$ referentes à localização das usinas, localização da rede elétrica, custos de geração, investimentos em projetos de cogeração e E2G, capacidade nominal de geração, dentre outros. A união desses indicadores primários e secundários serão apresentados em dois mapas temáticos gerados por meio do software TransCad versão 4.5, sendo eles:

- Moagem de cana-de-açúcar na safra 2013/14 mesorregionalizada ${ }^{6}$, localização das unidades produtivas e relação da disponibilidade de bagaço e palha de cana-de-açúcar na safra 2013/14.

- Localização e capacidade instalada das unidades produtivas mesorrregionalizada e localização das distribuidoras e redes de transmissão de energia no SIN.

Além dos mapas temáticos, foram gerados indicadores agronômicos, tecnológicos e mercadológicos mesorregionalizados a partir das informações obtidas no levantamento primário.

Quanto à representatividade amostral, foram obtidas respostas de 77 usinas, cuja representatividade pode ser verificada na Tabela 1 .

5. CTC Benchmarking - Banco de dados interno do Centro de Tecnologia Canavieira contendo, desde 2004, informações mensais agrícolas e industriais de uma amostra de usinas do Brasil.

6. Mesorregião segundo critério do Instituto Brasileiro de Geografia e Estatística (IBGE). 


\section{Resultados e discussão}

O conhecimento da localização das regiões de oferta e demanda por biomassa é essencial e primário para a identificação dos principais centros de influência a oferta de matéria-prima para geração de energia elétrica excedente e etanol celulósico. A Figura 3 possibilita uma análise macro das principais mesorregiões fornecedoras de biomassa de cana-de-açúcar, bem como as com maior potencial energético (elétrica ou etanol celulósico) para localização de futuras instalações ou ampliação do parque existente.

A partir da Figura 3 verifica-se que as mesorregióes de Ribeirão Preto e São José do Rio Preto são as que apresentam maior capacidade de fornecimento de biomassa de cana-de-açúcar, vinculada diretamente à capacidade produtiva de tais regionais. Além das mesorregiões do estado de São Paulo, destacam-se as regionais do Triângulo Mineiro/Alto Parnaíba e Sul Goiano como as principais produtoras de biomassa canavieira. Essa análise preliminar permite inferências quanto à identificação das usinas e municípios com maior incentivo à investimentos em expansão da capacidade de cogeração ou em projetos de etanol celulósico.

Outro mapa temático proposto no estudo diz respeito à identificação das mesorregiões com maior potencial de geração relativo ao nível tecnológico disponível, ou no presente trabalho, sua potência nominal (MW). A Figura 4 expõe a capacidade nominal instalada para geração de energia do setor sucroenergético nas mesorregiões da região Centro-Sul do Brasil, evidenciando em termos de localização a proximidade entre as distribuidoras, geradoras sucroenergéticas e linhas de transmissão do Sistema Interligado Nacional.

A Figura 4, visualmente, reforça um dos benefícios da energia de biomassa de cana-de-açúcar, a proximidade dos centros consumidores. Essa característica permite que, comparativamente a outras alternativas energéticas, os investimentos em geração e transmissão sejam menores e mais ramificados. Tal característica mostra-se importante uma vez que a energia elétrica é um bem de complexa classificação, podendo ser analisada como um bem público - a maior parte das firmas não tem intenção de realizar a atividade de geração; ou como um bem privado - o consumo de um agente restringe a demanda do outro; ou como um bem não estocável - necessidade de perfeita integração, coordenação e equilíbrio das forças de oferta e demanda, uma vez que o armazenamento de energia é complexo; ou não podendo ser classificada como commodity pois trata-se de um produto não comercial em escala internacional, apesar de ser um bem homogêneo (SOUZA, 2003).

Figura 3. Produção e disponibilidade de biomassa (mil t) de cana-de-açúcar no Brasil, safra 2013/14
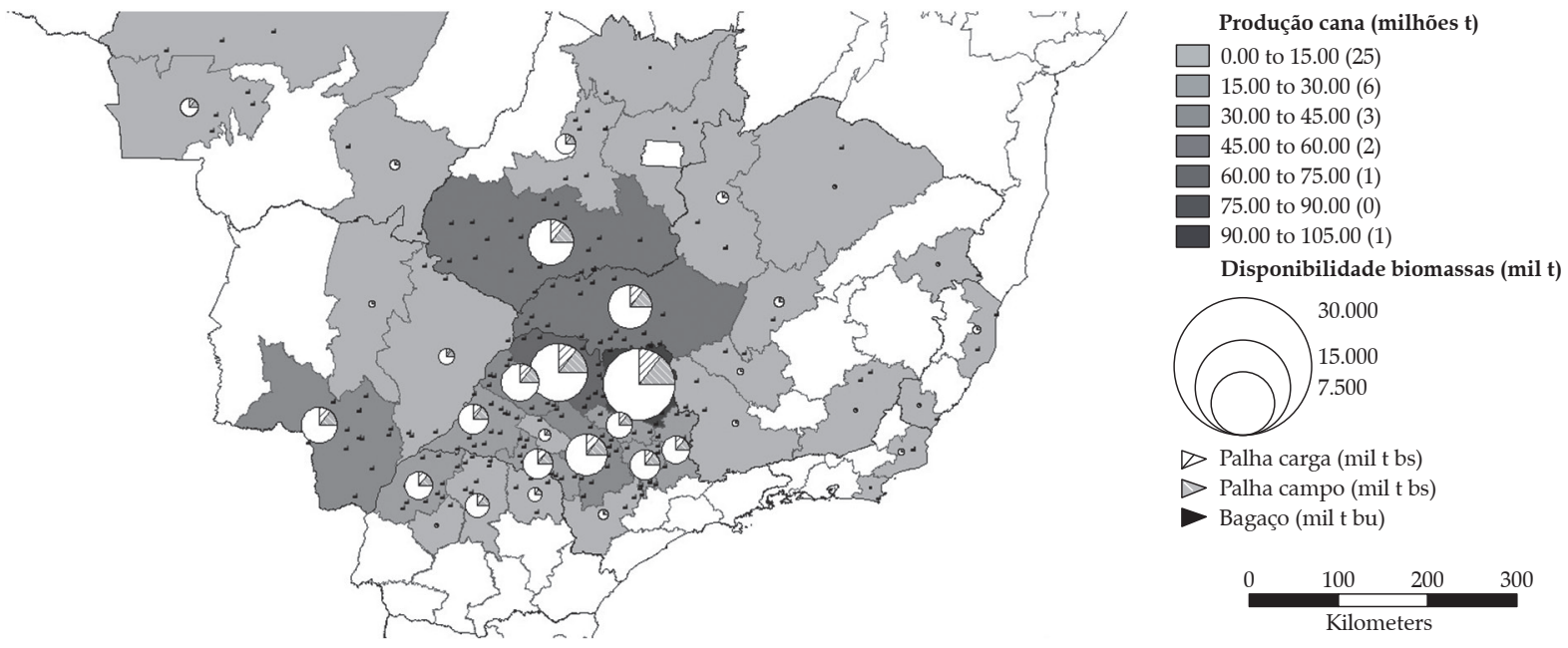

Nota: *bu - base úmida (40\%) bs - base seca (15\%).

Fonte: Trombeta (2015), a partir de Unica (2014). 
Figura 4. Setor sucroenergético: capacidade nominal (MW) de geração de energia elétrica nas mesorregiões do Centro-Sul do Brasil

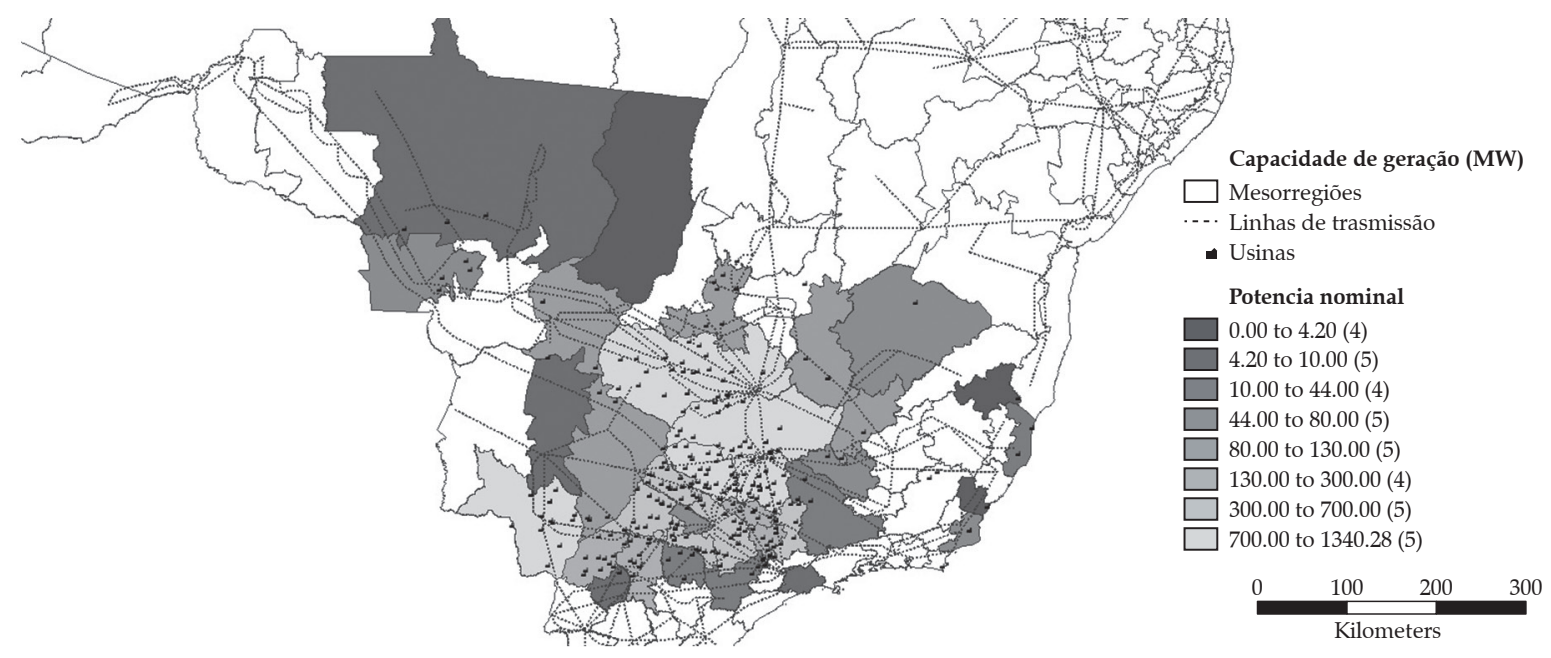

Fonte: Trombeta (2015), a partir de Anell (2014).

Nesse sentido, a proximidade entre os centros fornecedores de energia (usinas de cana-de-açúcar) e centros consumidores implica menor custo relativo de transmissão de energia à rede, maior controle da logística de fornecimento e equilíbrio da oferta de demanda por energia. Além disso, apesar de a energia não ser um bem estocável, a energia elétrica a partir de biomassa de cana possui uma matéria-prima armazenável que pode ser flexivelmente manejada ao longo de todo ano, dando maior autonomia energética a essa solução.

As regiões de maior capacidade nominal instalada localizam-se nas mesmas regionais identificadas na Figura 3. Esse comportamento é coerente, uma vez que em tais regionais evidencia-se alta concentração de unidades produtivas e maior capacidade de processamento médio mesorregional.

\subsection{Indicadores agronômicos}

Os indicadores agronômicos abordados nesse estudo referem-se às variáveis que interferem na disponibilidade de biomassa de cana-de-açúcar ao longo do ano-safra das usinas. Para isso, foram levantadas informações como duração da safra, percentual de impurezas vegetais - diretamente ligado à quantidade de palha solta trazida na carga e disponível ao sistema - percentual de impurezas minerais, moagem, área cultivada e produtividade agrícola. Nesse sentido, pode- -se considerar que, para a amostra obtida na pesquisa, uma usina média típica no Brasil apresentaria os indicadores agronômicos apresentados na Tabela 2 .

De modo geral, os indicadores agronômicos para uma usina típica no Brasil apresentam moagem média de 3 milhões de toneladas de cana, 8,1\% de impureza vegetal e $88 \%$ de colheita mecanizada (Tabela 2 ).

Mesorregionalmente, os mesmos indicadores médios podem ser visualizados na Tabela 3. Deve-se ressaltar que estes indicadores, tanto nacionais quanto mesorregionais, consistem em uma média disponibilizada por usina, podendo, em nível operacional da unidade, apresentar grande variação de acordo com o ambiente de produção dos talhões, variedade de cana-de-açúcar, número de corte etc. De modo geral, verifica-se que a configuração de uma usina típica média entre as mesorregiões é bastante distinta. A diferença entre as mesorregiões com períodos de safra mais longos e curtos é de 18 dias e os maiores níveis de moagem médio se dão nas mesorregiões de Ribeirão Preto, São José do Rio Preto e Sul Goiano. No que se diz respeito à colheita de cana mecanizadamente, exceto para as mesorregionais Central Mineira, Piracicaba e Campinas, os indicadores ficaram acima de $80 \%$ de colheita de cana crua (Tabela 3).

Outro indicador pertinente refere-se às impurezas minerais, cuja amplitude é de 1,48\% entre as mesorregionais amostradas (Tabela 3). Uma vez que esta causa, 
Tabela 2. Indicadores agronômicos médios na região Centro-Sul do Brasil

\begin{tabular}{lc}
\hline \multicolumn{1}{c}{ Variáveis } & Indicadores médios \\
\hline Dias de Safra (dias) & 246 \\
Moagem Média (t) & 2.930 .113 \\
Área Colhida (ha) & 35.714 \\
Produtividade Média (t/ha) & 83 \\
Cana Crua (\%) & $88 \%$ \\
Cana Queimada (\%) & $12 \%$ \\
Impureza Vegetal (\%) & $8,1 \%$ \\
Impureza Mineral (\%) & $1,3 \%$ \\
Estimativa Bagaço Disponível $(\mathrm{t})^{*}$ & 732.528 \\
Estimativa Palha Disponível $(\mathrm{t})^{* *}$ & 256.385 \\
\hline
\end{tabular}

Nota: * Bagaço a 50\% de umidade. ** Palha a 15\% umidade, aproveitamento de 50\%.

Fonte: Trombeta (2015).

Tabela 3. Indicadores agronômicos médios mesorregionais

\begin{tabular}{lccccccc}
\hline \multicolumn{1}{c}{$\begin{array}{c}\text { Mesorregiões da } \\
\text { pesquisa }\end{array}$} & $\begin{array}{c}\text { Dias } \\
\text { Safra }\end{array}$ & $\begin{array}{c}\text { Moagem } \\
\text { cana (t) }\end{array}$ & $\begin{array}{c}\text { Área } \\
\text { Colhida (ha) }\end{array}$ & Cana Crua & $\begin{array}{c}\text { Cana } \\
\text { Queimada }\end{array}$ & IV $^{\mathbf{1}}$ & IM $^{\mathbf{2}}$ \\
\hline Araçatuba & 243 & 2.193 .500 & 26.777 & $94 \%$ & $6 \%$ & $6,87 \%$ & $1,34 \%$ \\
Araraquara & 248 & 2.596 .367 & 28.603 & $96 \%$ & $4 \%$ & $8,82 \%$ & $1,45 \%$ \\
Assis & 257 & 2.879 .705 & 37.856 & $82 \%$ & $18 \%$ & $6,35 \%$ & $1,24 \%$ \\
Bauru & 249 & 2.877 .456 & 37.419 & $91 \%$ & $9 \%$ & $8,22 \%$ & $1,49 \%$ \\
Campinas & 249 & 2.220 .715 & 31.952 & $79 \%$ & $21 \%$ & $7,07 \%$ & $1,44 \%$ \\
Central Mineira & 255 & 2.044 .514 & 28.715 & $72 \%$ & $28 \%$ & $8,74 \%$ & $0,99 \%$ \\
Noroeste de Minas & 239 & 2.471 .290 & 26.000 & $100 \%$ & $0 \%$ & $11,40 \%$ & $1,00 \%$ \\
Piracicaba & 241 & 2.247 .764 & 27.191 & $76 \%$ & $24 \%$ & $10,00 \%$ & $1,90 \%$ \\
Presidente Prudente & 253 & 3.279 .495 & 47.479 & $83 \%$ & $17 \%$ & $8,17 \%$ & $2,24 \%$ \\
Ribeirão Preto & 244 & 3.872 .902 & 41.728 & $86 \%$ & $14 \%$ & $7,16 \%$ & $1,11 \%$ \\
São José do Rio Preto & 249 & 3.430 .089 & 40.850 & $87 \%$ & $13 \%$ & $11,34 \%$ & $1,62 \%$ \\
Sudeste MT & 240 & 2.537 .013 & 35.328 & $94 \%$ & $6 \%$ & $11,00 \%$ & $2,00 \%$ \\
Sudoeste de MS & 246 & 2.858 .810 & 43.240 & $93 \%$ & $7 \%$ & $8,64 \%$ & $1,24 \%$ \\
Sul Goiano & 250 & 3.526 .618 & 42.584 & $99 \%$ & $1 \%$ & $8,57 \%$ & $0,76 \%$ \\
Triângulo Mineiro & 239 & 2.413 .435 & 28.450 & $93 \%$ & $7 \%$ & $7,25 \%$ & $0,93 \%$ \\
\hline
\end{tabular}

Nota: ${ }^{1}$ Impureza Vegetal (\%), ${ }^{2}$ Impureza Mineral (\%).

Fonte: Trombeta (2015).

de modo geral e dentre outros fatores, diminuição da queima de sólidos suspensos, aumento da formação de cinzas nas caldeiras e maior frequência de manutenção dos equipamentos de cogeração, esse indicador deve ser minimizado nas unidades.

Já para as impurezas vegetais, encontradas na carga de cana-de-açúcar, essas indicam aporte direto de palha no sistema de processamento da usina. A quantidade de impureza vegetal muitas vezes pode ser estratégica à usina, dependendo da necessidade de biomassa, da quantidade de área própria, de legislações de transporte ou mesmo do raio de recolhimento.
Nesse sentido, cabe destacar que a rota de recolhimento de palha solta implica, de modo geral, o carregamento de maior quantidade de palha junto à massa de cana-de-açúcar retirada em sua operação de colheita. A fim de trazer maior quantidade de impurezas vegetais junto à carga, a velocidade dos extratores das colhedoras de cana é modificada ou desligada, fazendo com que a palha, ou a impureza vegetal, não seja separada da matéria-prima em colheita. De modo geral, a fase industrial, quando existente, para essa rota de recolhimento de palha, consiste no investimento denominado como sistema de limpeza a seco, 
no qual ocorre a separação da massa de palha da massa de cana por meio de um conjunto de ventiladores. A massa de cana segue para seu destino final que é a moenda, dando continuidade à fabricação de açúcar e etanol. A massa separada de palha aloca-se em uma câmara de despressurização da estrutura do sistema de limpeza e posteriormente é incorporada à massa de bagaço de cana-de-açúcar que seguirá para a caldeira (TROMBETA, 2015).

Os sistemas de limpeza a seco surgiram, especialmente, após o vigor da Lei no 11.241 de proibição da queimada de cana-de-açúcar. Nesse sentido, a necessidade da mecanização da colheita cultura implicou o surgimento de uma nova matéria-prima à usina: cana picada e crua em contrapartida aos colmos inteiros e sem impurezas vegetais (cana queimada). Os sistemas de limpeza anteriores à legislação tinham como característica o uso de água para limpeza da matéria-prima como processo antecedente à moagem da cana-de-açúcar. Com a nova matéria-prima, segmentada, o uso de água implica a perda considerável de açúcar, elegendo os sistemas de limpeza de cana a seco como a tecnologia mais adequada ao novo contexto do setor (TROMBETA, 2015).

Independente do aproveitamento da palha oriunda das cargas de colheita de cana-de-açúcar, os sistemas de limpeza a seco são fundamentais para limpeza adequada dos colmos e manutenção de índices adequados de eficiência industrial para o processamento da cana.

Além da palha solta, o estudo buscou a quantificação do potencial de fornecimento de biomassa de cana-de-açúcar mesorregional, que pode ser verificado na Tabela 4 para uma usina média.

Conforme supracitado, o indicador de impureza vegetal remete-se à palha de cana-de-açúcar que diretamente entra no sistema industrial a partir da colheita mecanizada da cana. Após a colheita, ficam no campo cerca de $75 \%$ da palha presente na cana-de-açúcar. $\mathrm{O}$ recolhimento dessa palha se dá por uma nova operação de colheita, cujo processo mais comumente utilizado no setor é o enfardamento (TROMBETA, 2015).

Nesse sentido, diferentemente da rota de recuperação de palha solta, na qual a matéria-prima é recolhida nos transbordos juntamente à massa de cana-de-açúcar colhida, o enfardamento consiste numa série de operações agrícolas visando a retirada de parte da palha remanescente no campo, após a colheita de cana. Com isso, o processo para obtenção de 1 tonelada de palha enfardada mostra-se mais complexo, exigindo sincronismo e integração de operações semelhantemente à colheita de cana-de-açúcar.

Para o enfardamento, as principais operações agrícolas referem-se a: 1 . Aleiramento da palha seca (as operações do enfardamento iniciam-se após 7 dias da colheita da cana); 2. Enfardamento; 3. Transporte

Tabela 4. Indicadores agronômicos médios mesorregionais: disponibilidade de biomassa de cana-de-açúcar para uma usina média

\begin{tabular}{lccc}
\hline \multicolumn{1}{c}{ Mesorregiões } & $\begin{array}{c}\text { Disponibilidade Bagaço } \\
(\mathbf{t})\end{array}$ & $\begin{array}{c}\text { Disponibilidade Palha } \\
\text { Solta }(\mathbf{t})\end{array}$ & $\begin{array}{c}\text { Disponibilidade Palha } \\
\text { Enfardada (t) }\end{array}$ \\
\hline Araçatuba & 548.375 & 76.773 & 115.159 \\
Araraquara & 649.092 & 90.873 & 136.309 \\
Assis & 719.926 & 100.790 & 151.185 \\
Bauru & 719.364 & 100.711 & 151.066 \\
Campinas & 555.179 & 77.725 & 116.588 \\
Central Mineira & 511.128 & 71.558 & 107.337 \\
Noroeste de Minas & 617.823 & 86.495 & 129.743 \\
Piracicaba & 561.941 & 78.672 & 118.008 \\
Presidente Prudente & 819.874 & 114.782 & 172.173 \\
Ribeirão Preto & 968.225 & 135.552 & 203.327 \\
São José do Rio Preto & 857.522 & 120.053 & 180.080 \\
Sudeste MT & 634.253 & 88.795 & 133.193 \\
Sudoeste de MS & 714.703 & 100.058 & 150.088 \\
Sul Goiano & 881.654 & 123.432 & 185.147 \\
Triângulo Mineiro & 603.359 & 84.470 & 126.705 \\
\hline
\end{tabular}

Fonte: Trombeta (2015). 
Interno dos fardos até o carreador; 4. Carregamento dos fardos e 5. Transporte Rodoviário dos Fardos.

Industrialmente, o processamento de fardos deve considerar um sistema que proporcione a adequada recepção dos fardos na usina, a remoção dos barbantes, desenfardamento, limpeza de impurezas minerais, trituração da palha e direcionamento às esteiras orientadas às caldeiras da usina (TROMBETA, 2015).

A adoção de uma ou mais rotas de recolhimento de palha dependerá de alguns fatores como raio de recolhimento médio, disponibilidade industrial, proporção de área de cana própria e fornecedores e da estratégia da usina.

No que se diz respeito à pesquisa, para ambas rotas de recolhimento de palha citadas, apenas 17 usinas responderam que apresentam estrutura industrial específica para o processamento de palha de cana-de-açúcar, representando $22 \%$ da amostra total. Dessa categoria, 13 usinas utilizam a rota de aproveitamento da palha de forma solta (cuja limpeza ocorre por meio dos sistemas de limpeza a seco), três usinas utilizam a rota do enfardamento e uma usina apresenta um sistema híbrido com a integração das rotas. Esse resultado evidencia, para esse estudo, que as tecnologias de recolhimento e processamento de palha ainda devem ser internalizadas de forma mais efetiva pelas usinas no curto e médio prazo, suavizando as curvas de aprendizagem inerentes a esse processo e aumentando a competitividade da palha na cadeia de valor do setor sucroenergético.

\subsection{Indicadores tecnológicos}

No que se diz respeito aos indicadores tecnológicos vinculados aos equipamentos industriais de cogeração de energia de biomassa de cana-de-açúcar na região Centro-Sul, foram amostradas 222 caldeiras e 221 turbogeradores. Além disso, obteve-se o consumo de energia médio e energia exportada média no Brasil e nas mesorregionais contempladas no estudo. As Figuras 5, 6 e 7 ilustram tais indicadores nacionais.

A partir da Figura 5 nota-se que a participação das caldeiras de alta pressão tem aumentado nos últimos anos, reflexo do investimento das unidades produtivas na segurança energética e possibilidade de receitas adicionais com a venda de energia elétrica. Apesar disso, ainda se verifica grande quantidade de caldeiras com baixa pressão de vapor (38\% da amostra), com
Figura 5. Setor sucroenergético: tecnologia de caldeira e capacidade de geração de pressão de vapor (bar)

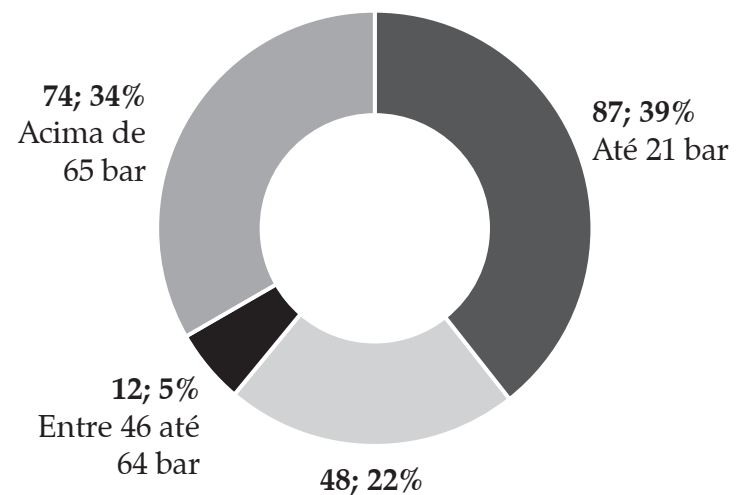

Entre 22 até 45 bar

Fonte: Trombeta (2015).

Figura 6. Setor sucroenergético: tecnologia de turbogeração

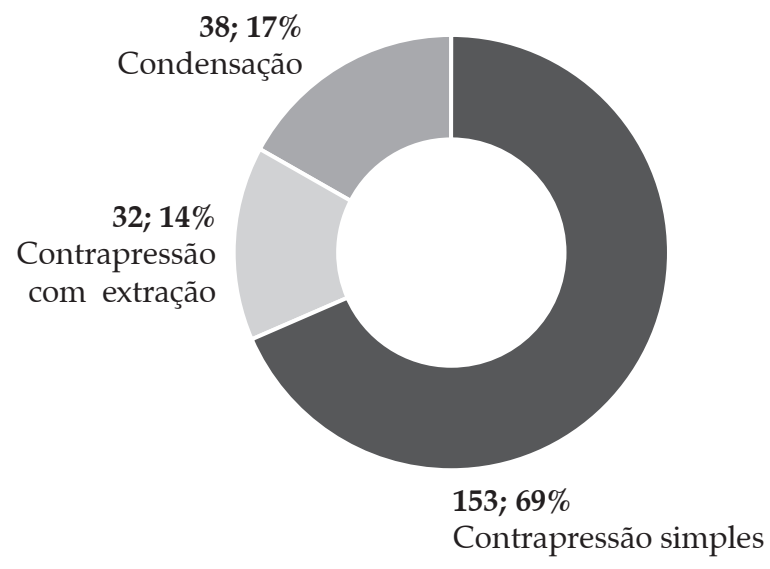

Fonte: Trombeta (2015).

Figura 7. Setor sucroenergético: consumo e geração de energia médios

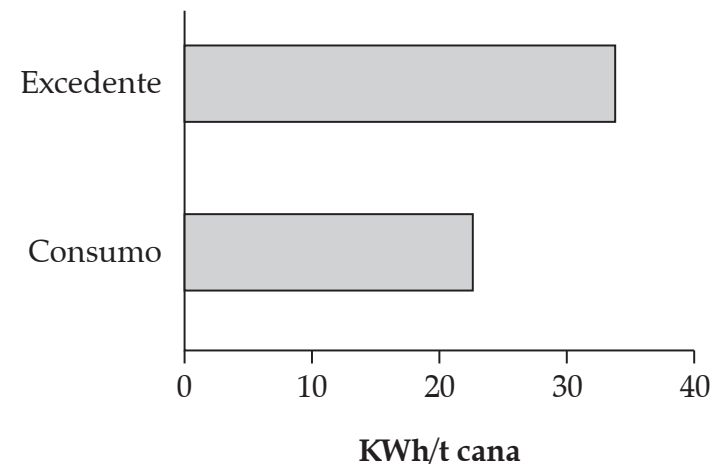

Fonte: Trombeta (2015) 
geração ínfima de vapor a ser utilizada para exportação de energia elétrica.

Em relação à tecnologia industrial de turbogeração, a Figura 6 mostra a dispersão dos tipos de turbogeradores levantados na pesquisa.

Conforme já descrito na fundamentação teórica, as tecnologias de turbogeração à condensação proporcionam menor consumo energético do sistema produtivo e melhor aproveitamento de vapor para geração de energia na entressafra, possibilitando, com isso, maior exportação média à rede elétrica. Entretanto, a tecnologia de contrapressão simples $(69 \%)$ foi a predominante na amostragem.

Apesar de esse indicador mostrar baixa evolução tecnológica no que se diz respeito ao tipo de turbogeração, tal tecnologia não é restritiva a ponto de prejudicar o potencial exportador de energia elétrica de uma unidade padrão.

Quanto ao consumo e à exportação de energia, a Figura 7 ilustra os indicadores médios para a região Centro-Sul.

Os mesmos indicadores anteriormente apresentados para a região Centro-Sul do Brasil podem ser verificados em nível mesorregional nas Tabelas 5, 6 e 7 .

A partir dos resultados verificados na Tabela 5, nota-se que as mesorregionais localizadas nas regiões denominadas como áreas de expansão (MS, MT, GO e $\mathrm{MG}$ ) apresentaram maior nível tecnológico para o parâmetro de caldeiras, evidenciando maior produção média de vapor e potencial de exportação de energia elétrica ao Sistema Interligado Nacional (SIN).

Para as usinas localizadas nas mesorregiões do estado de São Paulo, verifica-se maior incidência de caldeiras com baixa pressão de vapor. A tendência supracitada nesse resultado não surpreende, uma vez que as usinas na área de expansão são mais novas, construídas em um contexto setorial favorável (com a presença da bioeletricidade) e com maiores níveis de investimento relativo.

Já a Tabela 6 classifica as mesorregiões amostradas de acordo com o tipo de tecnologia de turbogeração. Diferente do que foi verificado para as caldeiras, o nível tecnológico predominante é o de turbogeradores do tipo de contrapressão simples, os quais, de modo geral, tendem a apresentar menor rendimento em termos de conversão da energia mecânica em elétrica.

Conforme já citado no indicador nacional para essa variável, verifica-se a adoção mais lenta pelos turbogeradores de condensação, os quais têm como principal vantagem o menor consumo energético de vapor, proporcionando a geração de energia no período de entressafra. Para as unidades que adotam essa estratégia, a reserva de biomassa, seja bagaço armazenado ou palha enfardada, deve ser planejada.

Por fim, a Tabela 7 destaca os indicadores de potência instalada média, consumo e excedente potencial de energia nas mesorregiões. De modo análogo ao verificado na Tabela 5, a Tabela 7 reforça o maior potencial

Tabela 5. Indicadores tecnológicos médios mesorregionais - caldeiras

\begin{tabular}{lcccc}
\hline \multicolumn{1}{c}{ Mesorregiões da pesquisa } & Até $\mathbf{2 1}$ bar & $\mathbf{2 2}$ a $\mathbf{4 5}$ bar & $\mathbf{4 6}$ a $\mathbf{6 4}$ bar & Acima de $\mathbf{6 5}$ bar \\
\hline Araçatuba & $31 \%$ & $13 \%$ & $0 \%$ & $56 \%$ \\
Araraquara & $76 \%$ & $6 \%$ & $0 \%$ & $18 \%$ \\
Assis & $18 \%$ & $53 \%$ & $12 \%$ & $18 \%$ \\
Bauru & $56 \%$ & $19 \%$ & $0 \%$ & $25 \%$ \\
Campinas & $55 \%$ & $0 \%$ & $0 \%$ & $45 \%$ \\
Central Mineira & $0 \%$ & $0 \%$ & $0 \%$ & $100 \%$ \\
Noroeste de Minas & $0 \%$ & $0 \%$ & $0 \%$ & $100 \%$ \\
Piracicaba & $64 \%$ & $0 \%$ & $7 \%$ & $29 \%$ \\
Presidente Prudente & $0 \%$ & $0 \%$ & $0 \%$ & $100 \%$ \\
Ribeirão Preto & $41 \%$ & $29 \%$ & $12 \%$ & $19 \%$ \\
São José do Rio Preto & $36 \%$ & $23 \%$ & $9 \%$ & $32 \%$ \\
Sudeste MT & $0 \%$ & $0 \%$ & $0 \%$ & $100 \%$ \\
Sudoeste de MS & $0 \%$ & $0 \%$ & $0 \%$ & $100 \%$ \\
Sul Goiano & $0 \%$ & $0 \%$ & $0 \%$ & $100 \%$ \\
Triângulo Mineiro & $11 \%$ & $89 \%$ & $0 \%$ & $0 \%$ \\
\hline
\end{tabular}

Fonte: Trombeta (2015). 
Tabela 6. Indicadores tecnológicos médios mesorregionais - turbogeradores

\begin{tabular}{lccc}
\hline \multicolumn{1}{c}{ Mesorregióes da pesquisa } & $\begin{array}{c}\text { Contrapressão } \\
\text { simples }\end{array}$ & $\begin{array}{c}\text { Contrapressão com } \\
\text { extração }\end{array}$ & Condensação \\
\hline Araçatuba & $71 \%$ & $6 \%$ & $24 \%$ \\
Araraquara & $91 \%$ & $0 \%$ & $9 \%$ \\
Assis & $53 \%$ & $33 \%$ & $13 \%$ \\
Bauru & $65 \%$ & $10 \%$ & $26 \%$ \\
Campinas & $71 \%$ & $7 \%$ & $21 \%$ \\
Central Mineira & $33 \%$ & $33 \%$ & $33 \%$ \\
Noroeste de Minas & $67 \%$ & $0 \%$ & $33 \%$ \\
Piracicaba & $56 \%$ & $31 \%$ & $13 \%$ \\
Presidente Prudente & $0 \%$ & $67 \%$ & $33 \%$ \\
Ribeirão Preto & $75 \%$ & $10 \%$ & $15 \%$ \\
São José do Rio Preto & $80 \%$ & $10 \%$ & $10 \%$ \\
Sudeste MT & $50 \%$ & $50 \%$ & $0 \%$ \\
Sudoeste de MS & $60 \%$ & $20 \%$ & $20 \%$ \\
Sul Goiano & $55 \%$ & $27 \%$ & $18 \%$ \\
Triângulo Mineiro & $100 \%$ & $0 \%$ & $0 \%$ \\
\hline
\end{tabular}

Fonte: Trombeta (2015).

Tabela 7. Indicadores tecnológicos médios mesorregionais - potência nominal, consumo e exportação de energia elétrica

\begin{tabular}{lccc}
\hline \multicolumn{1}{c}{ Mesorregióes da pesquisa } & $\begin{array}{c}\text { Potência média } \\
(\mathbf{M W})\end{array}$ & $\begin{array}{c}\text { Consumo de energia } \\
\text { (KWh/t) }\end{array}$ & $\begin{array}{c}\text { Excedente de energia } \\
\text { (KWh/t) }\end{array}$ \\
\hline Araçatuba & 21 & 24,58 & 42,15 \\
Araraquara & 11 & 17,38 & 17,84 \\
Assis & 16 & 18,80 & 24,92 \\
Bauru & 15 & 19,57 & 18,26 \\
Campinas & 13 & 23,05 & 36,51 \\
Central Mineira & 28 & 33,62 & 30,58 \\
Noroeste de Minas & 30 & 30,00 & 69,60 \\
Piracicaba & 13 & 16,28 & 23,53 \\
Presidente Prudente & 54 & 19,16 & 51,96 \\
Ribeirão Preto & 17 & 20,52 & 28,99 \\
São José do Rio Preto & 22 & 25,76 & 35,75 \\
Sudeste MT & 37 & 32,00 & 71,74 \\
Sudoeste de MS & 38 & 31,53 & 48,10 \\
Sul Goiano & 38 & 30,61 & 70,72 \\
Triângulo Mineiro & 15 & 19,41 & 27,16 \\
\hline
\end{tabular}

Fonte: Trombeta (2015).

de cogeração de energia elétrica verificado nas mesorregiões localizadas nas áreas denominadas como de expansão do cultivo de cana-de-açúcar no Brasil. Nesse sentido, as mesorregiões com maior produção de excedente de energia elétrica são sudeste de Mato Grosso, sul goiano e noroeste de Minas.

Pontualmente, nota-se que para as regiões do sul goiano e do sudoeste de Mato Grosso do Sul, os parâ- metros de caldeira, capacidade instalada e tecnologia de turbogeração são semelhantes; no entanto, o excedente energético dessa segunda regional é menor. Tal resultado é verificado em virtude de uma das usinas da amostra para a regional do sudoeste de Mato Grosso apresentar capacidade ociosa tecnológica ou limitadores de biomassa que impedem a máxima produção energética da unidade. 


\subsection{Indicadores de mercado}

Finalizando as análises relativas ao levantamento primário e secundário do mercado potencial de aproveitamento de biomassa de cana-de-açúcar, apresentam-se os indicadores mercadológicos. Tais indicadores referem-se à energia média comercializada e entregue ao Sistema Interligado Nacional, aos preços recebidos pela energia em leilões e no mercado livre - bem como à proporção de venda em ambos mercados - preços pagos para aquisição de bagaço (custo de oportunidade da biomassa), geração de energia na entressafra e restrição quanto ao limite de $30 \mathrm{MW}$ para obtenção de desconto para uso da rede. Nesse grupo de indicadores, são apresentados somente os valores médios nacionais referentes à região Centro-Sul devido a falhas de preenchimento da amostragem entre as mesorregiões (a informação de preços, por muitas unidades, foi considerada sensível e não disponibilizada na pesquisa).

Nesse contexto, por meio da Tabela 8, podem ser verificados os indicadores médios de mercado para região Centro-Sul do Brasil. Verifica-se que uma usina média no Brasil exporta cerca de $140.000 \mathrm{MWh} / \mathrm{safra}$, cuja predominância de comercialização se deu por meio dos leilóes de energia a preços médios de R \$191,49/MWh.

No que se diz respeito à geração de energia na entressafra, das 77 usinas amostradas, $75 \%$, ou 58 usinas, exportaram energia elétrica ao Sistema Interligado Nacional na safra 2013/14. Quanto à possibilidade de geração de energia no período de entressafra, $71 \%$ das usinas exportadoras de energia indicaram essa tendência (Tabela 8).

Já o indicador relativo à limitação de exportação de energia pelas unidades em virtude da restrição de 30 MW máximos exportados para obtenção de desconto na TUSD, 43\% das unidades exportadoras da amostra indicaram tal limite, o que implica uma exportação de energia à rede aquém à capacidade de geração (Tabela 8).

\section{Conclusões}

Por meio dos resultados e informações apresentadas no presente trabalho foi possível inferir que as biomassas de cana-de-açúcar apresentam papel relevante no que se diz respeito à segurança energética da matriz brasileira e na geração de receitas ao setor canavieiro do País. Quanto à participação como matéria-prima na produção de etanol celulósico, mostrou-se ínfima para o contexto atual em virtude do baixo número de representantes e estágio inicial de desenvolvimento dessa tecnologia.

De modo geral, acredita-se que o levantamento das informações primárias contribuiu para um melhor entendimento da efetiva oferta de biomassa de cana-de-açúcar, para a atualização do nível tecnológico de cogeração de energia elétrica das unidades da região Centro-Sul e das tendências mercadológicas para a comercialização de energia elétrica.

Quanto aos indicadores gerados, as informações agronômicas evidenciaram que a colheita de cana-de-açúcar de forma mecanizada é predominante na região Centro-Sul, atingindo índices superiores a 70\% em todas as mesorregionais amostradas. Nesse contexto, o manejo da palha tem se tornado uma nova atividade a ser administrada pelas unidades produtivas com potencial energético ainda pouco explorado, uma vez que somente $22 \%$ das usinas apresentam estrutura especifica para processamento de palha.

Para os indicadores tecnológicos verificou-se que mais de 50\% das caldeiras amostradas evidenciou o uso de caldeiras com baixa pressão de vapor (abaixo de 45 bar) e $69 \%$ dos turbogeradores informados foram do tipo contrapressão simples, tecnologia de menor eficiência. Com a consolidação do produto bioeletricidade no setor na última década, o nível de investimento e adoção de tecnologias de maior eficiência

Tabela 8. Indicadores de mercado - potência nominal, consumo e exportação de energia elétrica

\begin{tabular}{lcc}
\hline \multicolumn{1}{c}{ Variável } & Indicadores Médios Brasil & Amostragem \\
\hline Exportação de Energia (MWh/safra) & 140.879 & 58 \\
Participação Leilão (\%) & $53,45 \%$ & 31 \\
Preço Leilão (R\$MW) & 191,49 & 31 \\
Participação Mercado Livre (\%) & $46,55 \%$ & 27 \\
Preço Mercado Livre (R\$/MW) & 230,64 & 18 \\
Preço Bagaço (R\$/t) & $\mathrm{R} \$ 75,41$ & 17 \\
\hline
\end{tabular}

Fonte: Trombeta (2015). 
energética tem se intensificado; porém, ainda se mostra como uma lacuna a ser explorada visando a exploração otimizada da biomassa de cana-de-açúcar. Nesse contexto, a atratividade mercadológica dos leilões de energia, viabilidade de produção de etanol celulósico no médio prazo, linhas de financiamento específicas e políticas públicas que valorizem os produtos gerados pelo setor são fundamentais para a evolução da participação das biomassas na matriz energética nacional e justificativa de novos investimentos (palha, cogeração, etanol celulósico).

Por fim, os indicadores mercadológicos evidenciaram que a energia elétrica a partir da queima das biomassas de cana-de-açúcar é um importante produto na geração de receitas para as usinas. A transparência na definição de preços e especificidade dos leilões de energia é pré-requisito para a competividade e sustentabilidade da bioeletricidade da cana-de-açúcar.

\section{Referências bibliográficas}

AGÊNCIA NACIONAL DE ENERGIA ELÉTRICA. Banco de Informação de Geração (BIG) - Matriz Energética. Disponível em:<www.aneel.gov.br $>$. Acesso em: 06 ago. 2014.

CÂMARA DE COMERCIALIZAÇÃO DA ENERGIA ELÉTRICA. Setor elétrico, instituições do setor, comercialização, leilões de energia e legislação. Disponível em: <http://www.ccee.org.br>. Acesso em: 01 jun. 2014.

CÂMARA DE COMERCIALIZAÇÃO DA ENERGIA ELÉTRICA. InfoMercado. Disponível em: <http:// www.ccee.org.br/portal/faces/pages_publico/o-quefazemos/infomercado?_adf.ctrl-state $=9$ vzaruf65_4\&_ afrLoop $=1386687527054338>$. Acesso em 05 jan. 2017.

COMPANHIA NACIONAL DE ABASTECIMENTO. Acompanhamento da safra brasileira, cana-de-açúcar. Brasília, 2014. Disponível em: <http://www.conab.gov. br>. Acesso em: 08 jan. 2015.

DANELON, A. F, XAVIER, C. E. O. e LIMA, R. A. S. A importância do mercado de bagaço para a economia sucroenergética e os impactos em setores interligados. In: CONGRESSO DA SOCIEDADE BRASILEIRA DE ECONOMIA, ADMINISTRAÇÃO E SOCIOLOGIA RURAL, 53. Anais... João Pessoa: SOBER, 2015, p. 1-20.

DANTAS FILHO, P. L. Análise de custos na geração de energia com bagaço de cana-de-açúcar: um estudo de caso em quatro usinas de São Paulo. 2009. 175 p. Dissertação (Mestrado em Energia) - Escola Politécnica, Universidade de São Paulo, São Paulo, 2009.

DEFILIPPI FILHO, L. C. Estudo de viabilidade do uso do palhiço para geração de energia na entressafra de uma usina sucroenergética. 2013. 133 p. Dissertação (Mestrado em Agroenergia) - Escola de Economia de São Paulo, Fundação Getúlio Vargas, São Paulo, 2013.

EMPRESA DE PESQUISA ENERGÉTICA. Plano Decenal de Energia 2023 (PDE 2023). Brasília: Ministério de Minas e Energia, 2015. Disponível em: <www.epe. gov.br>. Acesso em: 14 abr. 2015.

EMPRESA DE PESQUISA ENERGÉTICA. Plano Nacional de Energia 2030 (PNE 2030). Brasília: Ministério de Minas e Energia, 2006. Disponível em: <www.epe. gov.br>. Acesso em: 10 mar. 2014.

HASSUANI, S. J., LEAL, M. R. L. V. e MACEDO, I. C. Biomass power generation: sugarcane bagasse and trash. Piracicaba: PNUD-CTC, 2005. (Série Caminhos para Sustentabilidade, 1).

LEAL, M. R. L. V. et al. Sugarcane straw availability, quality, recovery and energy use: a literature review. Biomass \& Bioenergy, Aberdeen, v. 53, p. 11-19, 2013.

LOPES, O. A. Avaliação de métodos avançados de geração de energia elétrica na indústria de açúcar e bioenergia. 2013. 66 p. Dissertação (Mestrado na área de Agroenergia) Escola de Economia de São Paulo, Fundação Getúlio Vargas, São Paulo, 2013.

MILANEZ, A.Y. et al. Da promessa a realidade: como o etanol celulósico pode revolucionar a indústria da canade-açúcar - uma avaliação do potencial competitivo e sugestões de política pública. Brasília: BNDES, 2015. 58 p. (BNDES Setorial, 41).

OLIVEIRA, A. M. K. et al. Avaliação da viabilidade técnica e econômica da utilização de biomassas como fonte energética alternativa em fornos industriais. Revista de Economia e Agronegócio, Viçosa, v. 4, n. 1, p. 1-14, jan./mar. 2006.

OPERADOR NACIONAL DO SISTEMA ELÉTRICO. Histórico da operação. Disponível em: < http://www.ons. com.br/home >. Acesso em: 14 maio 2014.

PERDONÁ, R. C. Tecnologia de aumento de eficiência de geração de bioenergia. In: FÓRUM DE NOVAS TECNOLOGIAS EM BIOMASSA, 6., 2014. São Paulo. Página sustentável. São Paulo, 2014.

RENEWABLE FUELS ASSOCIATION. Ethanol Industry Outlook 2008-2014. Disponível em: <www.afdc.energy. gov/data > . Acesso em: 10 abr. 2015. 
SEABRA, J. E. A. Avaliação técnico-econômica de opções para o aproveitamento integral da biomassa de cana no Brasil. 2008. 274 p. Tese (Doutorado em Planejamento de Sistemas Energéticos) - Faculdade de Engenharia Mecânica, Universidade Estadual de Campinas, Campinas, 2008.

SOUZA, Z. J. Geração de energia elétrica excedente no setor sucroalcooleiro: entraves estruturais e custos de transação. 2003. 279 p. Tese (Doutorado em Engenharia de Produção) - Universidade Federal de São Carlos, São Carlos, 2003.

TROMBETA, N. C. Potencial e disponibilidade de biomassa de cana-de-açúcar na região Centro-Sul do Brasil: uma aplicação de modelos de localização ótima para fins energéticos Piracicaba, 2015. 149 p. Dissertação (Mestrado em Economia Aplicada) - Escola Superior de Agricultura “Luiz de Queiroz", Universidade de São Paulo, Piracicaba, 2015.

UNIÃO DA INDÚSTRIA DE CANA-DE-AÇÚCAR. Bioeletricidade: a energia verde e inteligente do Brasil. São Paulo, 2010. 15 p.

UNITED STATES DEPARTMENT OF AGRICULTURE. Foreign Agricultural Service - World Centrifugal Sugar: Production and Consumption. Disponível em: <www. usda.gov>. Acesso em: 10 abr. 2015. 